Ethiopian Journal of Environmental Studies \& Management 10(1): 64 - 74, 2017.

ISSN: 1998-0507

doi: http://dx.doi.org/10.4314/ejesm.v10i1.7

Submitted: October 11, 2016

Accepted: January 20, 2017

\title{
MAINTENANCE MANAGEMENT SOURCING STRATEGIES AND THE CONDITION OF TERTIARY INSTITUTION BUILDINGS IN LAGOS AND OGUN STATES, NIGERIA
}

\author{
*FAREMI, 0., ADENUGA, 0. AND AMEH, J. \\ Department of Building, Faculty of Environmental Sciences, University of Lagos, Akoka, \\ Lagos, Nigeria
}

\begin{abstract}
In the face of the deplorable state of buildings across the various tertiary institutions in Nigeria, the need to deploy appropriate maintenance management strategy cannot be overemphasized. However, sourcing decision for maintenance services remains a tough one for decision makers as different sourcing option suit different scenario. This study examines maintenance management sourcing strategy used in tertiary institutions and investigates the extent to which the physical and functional conditions of buildings are determined by the choice of maintenance strategy. A survey of fifteen tertiary institutions in Lagos and Ogun State, Nigeria was conducted. Structured questionnaire was administered to seventy-five (75) respondents comprising maintenance staff and users of tertiary institutions within the study area. A total of fifty-six (56) questionnaires were found to duly completed and useful representing $75 \%$ response rate. Descriptive and inferential statistical tools including, frequency tables, mean and independent samples T-test were employed to analyze collected data. The results revealed that out of the thirty (30) maintenance services investigated, thirteen (13) and seventeen (17) maintenance services had better physical and functional condition under insourced and outsourced maintenance strategies respectively. Also, there was no significant difference in the physical and functional conditions of tertiary institution buildings maintained through insourcing and outsourcing strategies. This study recommends various building elements and services that could be maintained under the insourcing and outsourcing maintenance management strategies respectively.
\end{abstract}

Key Words: In-sourcing, Outsourcing, Tertiary Institution, Buildings, Maintenance

\section{Introduction}

The maintenance management of buildings and allied infrastructures is an integral aspect of the overall management responsibility in any organisation or institution irrespective of the nature and scope of the core business activities of such organization or institution.
Ogunmakinde et al. (2013) posit that it is practically impossible to produce buildings which are maintenance free. Adenuga, Odusami and Faremi (2007) opine that although much can be done at the design stage to reduce the amount of maintenance work to be executed at the operation and

*Corresponding Author: Faremi, O.

Email: juliusfaremi@gmail.com 
maintenance phase of buildings, building deteriorate relative to the nature and characteristics of construction materials, method of construction, age, environmental conditions, usage, method of design and maintenance management system in place for the building.

The condition of buildings and its associated services (Marilyn, 2006; Smith, 2008; Hopland 2012) impact the performance of students and staff in an educational facility. Recent studies on the impact of school buildings on students health (Baker and Bernstein, 2012; Mcintyre, 2016) reveals that the condition of school buildings not only affect the academic performance of students but also impact their health and psychological wellbeing. Mcintyre (2016) posit that decaying school buildings have both physical and psychological consequences on all category of users. For any school building including those at institutions of higher learning to be safe and meet basic infrastructure objectives, the deployment of appropriate maintenance management strategy is essential.

From a strategic perspective, there are three strategies for procuring maintenance management services; insourcing, outsourcing or a combination of both in a hybrid sourcing arrangement. Wong (2008) explain that insourcing refers to the arrangement of providing services internally using own resources while outsourcing refers to the strategy of having third party vendors provide services for a fee over a period of time.. Gómez et al. (2009) opine that outsourcing involves the process of delegating one or more business functions to an external service provider.

Traditionally in Nigeria, building maintenance responsibility in tertiary institutions is carried out through the elements however generally insourcing approach of sourcing maintenance services. Usually, each institution has dedicated maintenance unit as part of the works and physical planning departments. Over the years however, in spite of the tertiary institutions having dedicated maintenance units or departments and the implementation of maintenance programs through insourcing approach, most of the buildings and infrastructures in the nation's tertiary institutions remain in a state of disrepair which undoubtedly has hindered the delivery of quality tertiary education in the country. Existing studies such as Ekundayo and Ajayi (2009), Adenuga (2012), and Abigo et al. (2012) identified inadequate funding for maintenance activities and mismanagement of the little funds available for maintenance of infrastructure as the underlying factors responsible for the decay that have characterized many public infrastructures in Nigeria. It is against this backdrop that some tertiary institutions in their attempts to be frugal in expenditure, have considered outsourcing as an option to cut costs, improve quality of service and efficiency, and meet the demands for greater accountability.

The decision to outsource or retain services in-house however can be quite a major one as it can ultimately affect maintenance crew productivity as well as the quality of personnel and services respectively (Faremi et al., 2013). Often times, decision makers in many tertiary institutions follow a rule of chance approach in outsourcing maintenance services and learn from the outcome later as studies investigating appropriate sourcing strategy for maintenance management of institutional buildings are limited. This trial and error approach often 
result in unsatisfactory outcome (Faremi et al., 2013). Premised on the foregoing this study set to investigate maintenance management strategies used in tertiary institutions and the extent to which the strategies impact the physical and functional conditions of the buildings.

\section{Statement of the Problem}

Investment in physical infrastructure and the provision of maintenance management services should be geared toward achieving the strategic objectives of an institution or organization, which largely aim at value creation (Kamarazaly, 2007). Rawlinson (2006) asserts that sourcing decision have a profound effect on the success or failure of projects. Jin et al. (2012) add that it is usually challenging for the decision maker to select appropriate sourcing option based on general adaptation for any specific set of buildings or services, as different type of sourcing option suit different scenario. The development of a systematic approach that can assist maintenance policy makers in decision making on the choice of most appropriate sourcing option for any particular maintenance service in an organization or institution is therefore vital.

Despite numerous research efforts on insourcing and outsourcing strategies, inadequate are studies that investigates the extent to which the physical and functional condition of buildings are influenced by the choice of building maintenance sourcing strategy, this then constitute a gap in literature. Such investigation could assist top management of tertiary institutions and building maintenance policy makers in choosing the right maintenance sourcing strategy that is capable of assisting them achieve improved maintenance services and consequently well maintained buildings in tertiary institutions.

\section{Aim of the Study}

The aim of the study is to assess the extent to which the physical and functional conditions of tertiary institution buildings are impacted by maintenance sourcing strategy.

\section{Objective of the Study}

To assess the physical and functional condition of tertiary institution buildings in Lagos and Ogun state based on maintenance sourcing strategy.

\section{Research Hypotheses}

There is no significant difference in physical and functional conditions of tertiary institution buildings maintained through insourcing and outsourcing strategies.

\section{Literature Review}

The execution of maintenance works is the practical realisation of all the management decisions, designs and dreams for maximizing the results of maintenance efforts. According to Adenuga (2010), maintenance works are complex in nature and are carried either by directly employed labour or by appointed contractors. Faremi et al. (2013) asserts that the decision to source maintenance management services can be made through insourcing, outsourcing or a hybrid of both insourcing and outsourcing. According to Atkin and Brooks (2009), the approach taken depends on the priority set by the organization for the services to be procured.

Insourcing or in-house option of procuring maintenance services refers to a form of service provision in which maintenance services is provided by a dedicated resource directly employed by the client organization, where monitoring and control of performance is normally conducted under the terms of conventional 
employer / employee relationship, although internal service-level agreements may be employed as regulating mechanisms (Kamarazaly, 2007). An in-house approach remains to deal internally with product or services that require skill and knowledge in order to serve customers better. APSE (2011) posits that insourcing was regarded as a means of delivering efficiency and savings in the face of mounting budgetary pressure.

Outsourcing on the other hand results from an economic climate, where the emphasis is on cost savings and increased profits where it can reduce costs and increase quality (especially for lean operations). Faced with intense global competition, operational risks, limited resources and new technologies, companies and organizations try to optimize their resource allocation and there are increasing numbers of companies and organizations who would like to outsource their 'non-core' activities, in order to reduce the risk of operation. These are activities where the risk of losing knowhow by outsourcing them is low. Brown and Fersht (2014) posit that Outsourcing is the act of obtaining services from an external source. Dawne (2011) further explain that the guiding principle of outsourcing is that non-core and even critical activities of an enterprise or organization could be handed over to companies with lower labour costs and with expertise in those activities, thereby freeing internal resources to focus on enhancing the value-add of the organizations core business. It can therefore be said that outsourcing can be seen as a process where firms assign some of its in-house tasks/activities or processes to a third party vendor.

The physical and functional states of buildings constitute the major characteristics by which the condition of building can be evaluated. Buildings once completed are expected to perform certain function for a certain period. However, a building must be maintained to keep it in optimal operation since is practically impossible to produce buildings which are maintenance free (Ajetomobi and Olanrewaju, 2015). The essence of building maintenance is therefore to increase the service life of a building by delaying deterioration, decay and failure. Building maintenance must therefore be considered as a strategic process if the value of a building is to be sustained (Idrus et al., 2009). Adenuga (2012) presents a comprehensive list of various building elements and maintenance services required for keeping a building well maintained. The listed elements and maintenance services can be categorized into four categories of building fabrics, services, environment and aesthetic. This study adopts the list of maintenance services as presented by the author for the purpose of evaluating the operational state of buildings within the study area.

\section{Methodology}

This study was conducted in Lagos and Ogun State, located in the South West Geo-Political Zone of Nigeria. The choice of the two states for this study was because Lagos State is the economic nerve centre of Nigeria with the largest concentration of industries, financial institutions and major sea ports. The human population of the state is in excess of 9 million people (National Population Commission, 2009). Lagos State is bounded on the North and East by Ogun State. In the West it shares boundaries with the Republic of Benin. Behind its southern borders lies the Atlantic Ocean. $22 \%$ of its $3,577 \mathrm{~km} 2$ are lagoons and creeks. On the other hand, 
Ogun State covers a total of $1,640,076$ Sq.Km of land mass where over 60 percent are cultivable arable land, with an estimated population of about 3.391million. This makes both states among the fastest growing cities in Nigeria with significant number of tertiary institutions which enhanced the collection of data for this study.

A structured questionnaire was designed and used as the principal instrument for collecting data for this study. Using purposive sampling technique, the first set of questionnaires were administered to maintenance resource persons in the maintenance departments while the second set of questionnaires were randomly administered to the users of buildings of the surveyed tertiary institutions within the study area.

A total of 75 questionnaires were administered, three (3) each to fifteen (15) institutions comprising Universities and Polytechnics in Lagos and Ogun States respectively. Out of the 75 administered questionnaires a total of 70 questionnaires were retrieved. The retrieved questionnaires were scrutinized for errors, omissions, completeness and inconsistencies after which only 56 were found to be adequately completed and therefore suitable for analysis representing
$75 \%$ response rate. The data collected was processed and analysed with the aid of Statistical Package for Social Sciences (SPSS) version 20.0. Frequency tables and mean score were used for the descriptive statistic while independent samples " $t$ " test were used to test the hypothetical statement formulated for this study.

\section{Results and Discussion}

Table 1 shows the characteristics of respondents for this study across four areas comprising the respondents' gender, respondents 'category, the state in which the institution of the respondents is located and the names of the institutions of those that responded to the survey. The analysis revealed that the population of male respondents was as twice as that of female with $64.3 \%$ and $32.1 \%$ respectively. Also, table 1 shows that $50 \%$ of the respondents were maintenance staff, $46.4 \%$ were users of buildings in the various tertiary institutions while about $4 \%$ of the respondents did not indicate their category. This distribution gives a balance of respondents between those handling maintenance responsibilities and those receiving maintenance services. It thus implies that there would be appropriate responses to the various formulated research questions. 
Maintenance Mana.qement Sourcing Strategies................FAREMI et al.

Table 1: Demographic data of respondents

\begin{tabular}{lll}
\hline Demographic Data & Frequency & Percentage \\
\hline Gender & 36 & \\
Male & 18 & 64.3 \\
Female & 2 & 32.1 \\
Missing System & 56 & 3.6 \\
Total & & 100.0 \\
& & \\
Respondent Category & 28 & \\
Maintenance Staff & 26 & 50.0 \\
Building Users & 2 & 46.4 \\
Missing System & 56 & 3.6 \\
Total & & 100.0 \\
& & \\
State Location of Institution & 25 & \\
Lagos & 29 & 44.6 \\
Ogun & 2 & 51.8 \\
Missing System & 56 & 3.6 \\
Total & & 100.0 \\
& & \\
Names of Institution & & \\
CRAWFORD & 4 & 7.1 \\
NOUN & 4 & 7.1 \\
BABCOCK & 4.1 \\
MAPOLY & 3 & 5.4 \\
UNILAG & 3 & 8.9 \\
CONVENANT & 5 & 5.4 \\
LAGOS CITY POLYTECHNIC & 4.1 \\
TASUED & 3 & 3.6 \\
CALEB & 2 & 8.9 \\
BELLS & 5.6 \\
LASPOTECH & 5.4 \\
LASU & 5.9 \\
FOU & 5.6 \\
YABAAB & 5.4 \\
Missing System & 5.9 \\
Total & 5.6 \\
\hline
\end{tabular}

Furthermore, table 1 reveals that $44.6 \%$ of the respondents are from tertiary institutions in Lagos state while $51.8 \%$ of the respondents were from tertiary institutions in Ogun state. The generality of these respondents were from fifteen tertiary institutions spread across Lagos and Ogun state and thus provide adequate basis for the generalisation of the findings of this study for tertiary institutions within the study area.

This study assesses the operational state of building elements and services across the tertiary institutions within the study area based on the choice of maintenance sourcing strategy. This was done to ascertain the physical and functional condition of key elements as 
well as essential services in the surveyed tertiary institutions with a view to determine the extent to which the operational state of the buildings are influenced by the maintenance sourcing strategy adopted by the respective institutions. The resulting analysis is presented in table 2 .

Table 2: Operational state of tertiary institution buildings

\begin{tabular}{|c|c|c|c|c|c|c|}
\hline \multirow[t]{2}{*}{ Building Systems and Elements } & \multicolumn{2}{|c|}{ Insourcing } & \multicolumn{2}{|c|}{ Outsourcing } & \multicolumn{2}{|c|}{ Hybrid } \\
\hline & $\mathrm{N}$ & Mean & $\mathrm{N}$ & Mean & $\mathrm{N}$ & Mean \\
\hline \multicolumn{7}{|l|}{ Building Fabric } \\
\hline Frames & 25 & 3.67 & 18 & 3.20 & 13 & 3.78 \\
\hline Upper floors & 25 & 3.78 & 18 & 4.24 & 13 & 3.89 \\
\hline Roofs & 25 & 3.40 & 18 & 4.68 & 13 & 3.44 \\
\hline Stairs & 25 & 3.78 & 18 & 4.85 & 13 & 3.44 \\
\hline External walls & 25 & 4.00 & 18 & 3.30 & 13 & 4.00 \\
\hline Windows and External Doors & 25 & 3.78 & 18 & 2.80 & 13 & 3.75 \\
\hline Internal walls and partitions & 25 & 3.70 & 18 & 3.15 & 13 & 4.11 \\
\hline Internal doors & 25 & 3.80 & 18 & 4.81 & 13 & 3.67 \\
\hline Wall finishes & 25 & 3.78 & 18 & 2.00 & 13 & 3.67 \\
\hline Floor finishes & 25 & 4.00 & 18 & 4.00 & 13 & 3.89 \\
\hline Ceilings & 25 & 3.90 & 18 & 1.90 & 13 & 3.89 \\
\hline Nettings & 25 & 4.00 & 18 & 3.10 & 13 & 3.50 \\
\hline Building Fabric Average & & 3.80 & & 3.50 & & 3.75 \\
\hline \multicolumn{7}{|l|}{ Services } \\
\hline Sanitary appliances & 25 & 4.00 & 18 & 3.33 & 13 & 3.60 \\
\hline Generators & 25 & 3.65 & 18 & 3.65 & 13 & 3.65 \\
\hline Disposal installation & 25 & 3.88 & 18 & 4.12 & 13 & 4.17 \\
\hline Water installation and plumbing & 25 & 4.07 & 18 & 4.50 & 13 & 4.00 \\
\hline Electrical installation & 25 & 4.20 & 18 & 3.00 & 13 & 4.00 \\
\hline Gas Installation & 25 & 3.91 & 18 & 3.57 & 13 & 3.00 \\
\hline Lifts and conveyor installation & 25 & 3.83 & 18 & 3.71 & 13 & 3.00 \\
\hline Protection installation & 25 & 3.75 & 18 & 3.88 & 13 & 4.33 \\
\hline Drainages & 25 & 3.56 & 18 & 4.00 & 13 & 3.00 \\
\hline External Services & 25 & 4.00 & 18 & 3.50 & 13 & 3.00 \\
\hline Ventilation system & 25 & 3.92 & 18 & 4.25 & 13 & 4.50 \\
\hline Services Average & & 3.89 & & 3.77 & & 3.66 \\
\hline \multicolumn{7}{|l|}{ Environment } \\
\hline General sanitation of the environment & 25 & 4.25 & 18 & 3.44 & 13 & 4.00 \\
\hline Lawns and Gardens & 25 & 4.00 & 18 & 3.50 & 13 & 2.00 \\
\hline Car park and parking lots & 25 & 4.05 & 18 & 3.25 & 13 & 2.00 \\
\hline Environment Average & & 4.10 & & 3.40 & & 2.67 \\
\hline \multicolumn{7}{|l|}{ Aesthetic } \\
\hline Fittings and furnishings & 25 & 3.64 & 18 & 5.00 & 13 & 4.00 \\
\hline Internal painting & 25 & 4.00 & 18 & 4.00 & 13 & 3.75 \\
\hline External painting & 25 & 3.93 & 18 & 4.00 & 13 & 3.88 \\
\hline External cornices on facades & 25 & 3.83 & 18 & 5.00 & 13 & 3.56 \\
\hline Aesthetic Average & & 3.85 & & 4.50 & & 3.80 \\
\hline
\end{tabular}


Table 2 revealed that the mean value for the operational state of building fabrics maintained by insourcing, outsourcing and hybrid maintenance strategies were 3.80 , 3.50 and 3.75 respectively. This implies that the buildings whose fabrics were maintained by in-house maintenance crew were rated to be better by the respondents. Although from the range of mean scores obtained from the analysis and presented in table 2 , it shows that the general physical and functional condition of building fabrics across the various tertiary institutions was mere average. The implication of a higher mean score for buildings whose building fabrics maintenance management were insourced is that the generality of building fabric elements maintained through insourcing were in better physical and functional conditions than those maintained through outsourcing and the hybrid strategies.

Similarly, the respondents perceived better physical and functional state for building services whose maintenance were carried out by in-house maintenance crew. This is reflected by the average mean of 3.89 for building services maintained through insourcing as against 3.77 and 3.66 which were the corresponding average mean values for building services maintained through outsourcing and hybrid respectively. In addition, the analysis of this study shows that for the external and environmental maintenance services investigated in the course of this study, insourcing maintenance strategy favours maintenance services all comprising cleaning services, lawns and gardens maintenance and the maintenance of parking lots with average mean values of $4.25,4.00$ and 4.05 respectively implying good physical and functional conditions for all three services. Whereas similar services under the outsourcing maintenance strategy and the hybrid maintenance sourcing strategies revealed average and poor physical and functional conditions respectively, especially for the maintenance management of lawns and gardens and car parks and parking lots

In contrast with earlier discussed building maintenance services categories of building fabrics, services and environmental services which shows the insourcing arrangement having better mean scores, the aesthetics category comprising fittings and furnishings, painting (both internal and external) and façade maintenance shows that the outsourcing strategy had an average mean score of 4.50 implying good physical and functional condition of those elements as against the average mean of 3.85 and 3.80 for those maintained by insourcing and hybrid respectively.

Furthermore, the analysis shows that most of the building systems and elements had mean scores ranging from 3.00 to 4.49 implying an average physical and functional condition. This result support the findings of Hines (1996) that the general physical and functional condition of most school buildings are below satisfactory. The findings in however in contrast with the findings of Lewis and Kaplan (2000) which posit that for schools in the United States of America, the perceived operational condition of about $56 \%$ of school was good implying that there are more schools having buildings with satisfactory physical and functional conditions than those with unsatisfactory physical and functional conditions.

\section{Test of Research Hypothesis}

$\mathrm{H}_{0^{-}}$There is no significant difference in the physical and functional conditions of tertiary institution buildings maintained 
through insourcing and outsourcing strategies.

$\mathrm{H}_{1}$ - There is significant difference in the physical and functional conditions of tertiary institution buildings maintained through insourcing and outsourcing strategies

Table 3: Independent Samples $\mathrm{T}$ test for physical and functional condition of maintenance services executed through insourcing and outsourcing.

\begin{tabular}{lllll}
\hline Building Elements/Services & \multicolumn{4}{l}{ t-test for Equality of Means } \\
& $\mathrm{t}$ & $\mathrm{df}$ & $\mathrm{Sig}$. (2-tailed) & Decision \\
\hline Building Fabrics & 0.89 & 8.00 & 0.18 & Ho Accepted \\
Electrical Installation & 1.16 & 19.00 & 0.13 & Ho Accepted \\
Plumbing/Water System Installation & -0.80 & 1.33 & 0.36 & Ho Accepted \\
Lifts and Conveyor Installation & 0.20 & 11.00 & 0.54 & Ho Accepted \\
Sanitary Appliances & -0.55 & 16.00 & 0.59 & Ho Accepted \\
Fire Protection Installation & -1.08 & 16.00 & 0.30 & Ho Accepted \\
General sanitation of the environment & 2.09 & 17.21 & 0.05 & Ho Accepted \\
Lawns and Gardens & 1.01 & 21.00 & 0.32 & Ho Accepted \\
\hline Average Significance Value & & & 0.309 & \\
\hline
\end{tabular}

Table 3 shows the results of the independent samples t test used to test the hypothesis of this study. An overall average significance value $\mathrm{p}=0.309$ was obtained. The obtained significance value was >0.05. The result implies an acceptance of the null hypothesis which infer that there is no significant difference in the physical and functional conditions of tertiary institution buildings maintained through insourcing and outsourcing strategies.

\section{Conclusion}

This study reveals that the general physical and functional condition of buildings and services in tertiary institutions in Lagos State and Ogun State was average irrespective of the adopted maintenance management sourcing strategy. Although the difference in the physical and functional conditions of the buildings in tertiary institutions maintained through insourcing and outsourcing maintenance strategy was not significant, the general outlook of the mean values of physical and functional conditions for building maintenance services comprising building fabrics, building services and environmental maintenance services shows higher mean scores when compared to the physical and functional conditions when such services were executed through outsourcing and hybrid maintenance strategies respectively. Although these differences was not statistically significant. This study also shows that fittings and furnishings, painting, both internal and external, external cornices and facade had relatively high mean scores implying better physical and functional conditions of these elements while the mean values for the physical and functional condition of installed building services such as sanitary appliances, disposal installations, electrical installations, ventilation systems etc. was observed to be the least among the four categories for assessing the physical and functional condition of buildings in tertiary institutions. These results suggest that 
while top management and maintenance crew of the various tertiary institutions are conscious of the physical appearance of their respective building exterior across the various campuses, installed systems and services within the buildings appear to be deteriorating.

This study recommend that maintenance crew of tertiary institutions should pay more attention to the maintenance of installed electrical and mechanical services within the tertiary institution buildings in other to preserve and keep them in good physical and functional condition. Furthermore, it is recommended that when considering services to be outsourced or retain inhouse, the maintenance of building elements and services such as building frames, external walls, internal doors, wall finishes, nettings, sanitary appliances, electrical installations, gas installation, lift and conveyor installations, external services, general sanitation of the environment, lawns and gardens, car park and parking lots should be given high priority under insourcing maintenance arrangement while the maintenance of elements and services such as upper floors, roofs, stairs, windows and external doors, internal walls and partitions, ceilings, disposal installation, water installation and plumbing, protection installation, drainages, ventilation systems, fittings and furnishings, external painting and external cornices should be given high priority when considering services to be outsourced.

\section{References}

Abigo, A., Madgwick, D., Gidado, K. and Okonji, S. (2012) "Strategic Approach to Maintenance Practices for Public Buildings in Lagos State”.
The Lagos Journal of Environmental Studies, 5(1): 20-28.

Adenuga, O.A. (2010). Labour Composition for Maintenance Works in Public Hospital Built Environment in South-West, Nigeria. Journal of Building Performance, 1(1): 83-92.

Adenuga, O.A. (2012). Maintenance Management Practices in Public Hospital Built Environment: Nigeria Case Study. Journal of Sustainable Development in Africa, 14(1): 228244.

Adenuga, O., Odusami, K. and Faremi, J. (2007). Assessment of Factors Affecting Maintenance Management of Public Hospital Buildings in Lagos State, Nigeria. In The Construction and Building Research Conference of the Royal Institution of Chartered Surveyors. Georgia Atlanta USA, 67.

Ajetomobi, O.O., and Olanrewaju, S.B. (2015). Evaluation of the Factors Affecting Housing Maintenance and its Probable Solutions. International Journal of Latest Research in Engineering and Technology, 1(4): 59-64.

APSE. (2011). Insourcing update: The Value of Returning Local Authority Services In-house in an era of Budget constraints. UNISON, 1-10.

Atkin, B. and Brooks, A. (2009). Total Facilities Management (Third). Wiley-Blackwell.

Baker, L. and Bernstein, H. (2012). The Impact of School Buildings on Student Health and Performance: A Call for Research. Research Foundation, 1-35.

Brown, D. and Fersht, P. (2014). The State of Services \& Outsourcing in 2014. 
Dawne, L. (2011). An Examination of Factors Motivating Hotel Outsourcing. International Journal of Hospitality Management, 30(4), 963973.

Ekundayo, H.T. and Ajayi, I.A. (2009), "Towards effective management of university education in Nigeria", International NGO journal, 4(8), 342347

Faremi, O.J., Adenuga, O.A. and John, I.B. (2013). Assessment of Factors Influencing Facility Management Procurement Route in Lagos State , Nigeria. Journal of Surveying, Construction \& Property, 4(1): 1-13.

Gómez, J., Crespo, A. and Moreu, P. (2009). Outsourcing Maintenance in Services Providers. Safety, Reliability and Risk Analysis: Theory, Methods and Applicationl. (Eds), 829-838.

Hines, E.W. (1996). Building Condition and Student Achievement and Behavior. Unplublished $\mathrm{PhD}$ Thesis, Virginia Polytechnic Institute and State University.

Hopland, A.O. (2012). School building conditions and student achievments : Norwegian evidence (2012 No. 2).

Idrus, A., Khamidi, M.F. and Lateef, O.A. (2009). Value - Based Maintenance Management Model for University Buildings in Malaysia-A Critical Review. Journal of Sustainable Development, 127-133.

Jin, S., Chua, L., Ali, A. S. and Alias, A. (2012). Selection of Procurement Method for Building Maintenance
Management: A Decision Making Model.

Kamarazaly, M.A. (2007). Outsourcing Versus In-house Facilities Management: Framework for Value Adding Selection. Unplished Master of Philosphy Thesis, Massey University at wellington, New Zealand. 1-148.

Lewis, L. and Kaplan, J. (2000). Condition of America's Public School Facilities : 2012-2013.

Marilyn, H. (2006). Best Practices Maintenance Plan for School Buildings.

Mcintyre, E. (2016). Decaying School Buildings have Physical, Psychological Consequences.

National Population Commission. (2009). 2006 Population and Housing Census of the Federal Republic of Nigeria. Official Gazette of the Federal Republic of Nigeria, 96(2), 1.

Ogunmakinde, O., Akinola, A. and Siyanbola, A. . (2013). Analysis of the Factors Affecting Building Maintenance in Government Residential Estates in Akure, Ondo State, Nigeria. Journal of Environmental Sciences and Resources Management, 5(2): 65-73.

Rawlinson, S. (2006). Successful projects.

Smith, S. M. (2008). School Building Quality and Student Performance in South Carolina Public High Schools.

Wong, S.F. (2008). Drivers of IT Backsourcing Decision. Communications of the IBIMA, 2, 102-108. 